\title{
Participation of Various Nuclei of the Hypothalamus in the Implementation of the Drinking Skill Developed
}

\author{
Rafiga Mazahir Baghirova* \\ Azerbaijan State Academy of Physical Education and Sport, Azerbaijan Republic
}

*Corresponding author: Rafiga Mazahir Baghirova, Department of Medical and Biological Sciences, Azerbaijan State Academy of Physical Education and Sports, Baku, Azerbaijan Republic

\begin{abstract}
ARTICLE INFO
Received: 幽 May 08, 2021

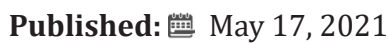

Citation: Rafiga Mazahir Baghirova. Participation of Various Nuclei of the Hypothalamus in the Implementation of the Drinking Skill Developed. Biomed J Sci \& Tech Res 35(5)-2021. BJSTR. MS.ID.005762.

Keywords: Various Nuclei of the Hypothalamus; Drinking Conditioned Reflex; Electrical Stimulation; Temporary Shut-

ABSTRACT

In order to study the role of various nuclei of the hypothalamus in the implementation of the drinking skill developed electrostimulation and temporary shutdown were performed supraoptic (SO), ventromedial (VMH) and medial-mamillary (MM) nuclei of the hypothalamus. The registration of the amount of consumed water showed the following: electrostimulation of SO, unlike VMH and MM of hypothalamic nuclei caused additional water consumption in comparison with the background. The application of novocaine in SO led to a significant decrease in the amount of water consumed, which decreased for the duration of the action of novocaine (40-50 minutes) and amounted to $60-70 \mathrm{ml}$ instead of 120 in the norm. Bilateral novocaine blockade of SO led to a complete inhibition of the performance of the developed drinking skill. Thus, the results of the studies carried out on electrical stimulation and temporary switching off of the $\mathrm{SO}$ suggest that the osmoreceptors of the $\mathrm{SO}$ of the anterior hypothalamus play a certain role in the processes of the formation of thirst.
\end{abstract} down
Abbreviations: SO: Supraoptic Nucleus of the Hypothalamus; VMH: Ventromedial Nucleus of the Hypothalamus; MM: Medial-Mammillary Nucleus of the Hypothalamus

\section{Introduction}

The hypothalamus is a small area in the diencephalon that includes a large number of cell groups (more than 30 nuclei) that regulate the neuroendocrine activity of the brain and homeostasis of the body [1-4]. The hypothalamus is connected by nerve pathways with almost all parts of the central nervous system, including the cortex, hippocampus, amygdala, cerebellum, brain stem, and spinal cord [5]. Together with the pituitary gland, the hypothalamus forms the hypothalamic-pituitary system, in which the hypothalamus controls the synthesis and secretion of many pituitary hormones, is the central link between the nervous and endocrine systems. It secretes hormones and neuropeptides and regulates functions such as hunger and thirst. body thermoregulation, sexual behavior, sleep and wakefulness (circadian rhythms) [1,2,6].

Recent studies show that the hypothalamus plays an important role in higher functions, such as memory and emotional state, and thus participates in the formation of various aspects of behavior $[2,7,8]$. The hypothalamus controls the activity of the human endocrine system, due to the fact that its neurons are able to secrete neuroendocrine transmitters (liberins and statins) that stimulate or inhibit the production of hormones from the adenohypophysis $[3,5]$. Suppression of the functional activity of the hypothalamus leads to a violation of drinking and eating behavior [9]. Considering all of the above, the task of this study was to study the role of various nuclei of the hypothalamus in the implementation of the drinking skill developed.

\section{Methods}

Experiments were performed using 20 rabbits breeds of "Chinchilla" in weight 2-3kg trained to perform a conditioned operant drinking behavior reflex. The animals were subjected to water deprivation for 24 and 48 hours, after which they were trained in the instrumental drinking skill. In response to the sound signal, the rabbit pressed the pedal, as a result of which the door opened, jumped over the barrier from the starting compartment of the chamber to its target section to receive water in a strictly defined 
dose $(5-10 \mathrm{ml})$ and then returned back to the starting section cameras. The conditioned stimulus was applied at regular intervals (every $45 \mathrm{~s}$ ) from 10 to 15 times during the experiment. During the experimental day, the animals received an average of 100-120 ml of water. The experiments were carried out under conditions of $100 \%$ reinforcement. In the study of behavioral reactions, the time from the moment the signal was given to the start of the jump (latency period), the time of running, lapping, and also the time spent on returning to the starting box of the camera were recorded.

Electrical stimulation of the supraoptic - SO (A-3; L2.2; H15.8), ventromedial - VMH (P1; L0.5; H17) and medial-mammillary - MM (A-3; L0.5; H18.5) nuclei of the hypothalamus of the brain was carried out using a universal electrostimulator ESU-1.

\section{Results and Discussions}

Observations of conditioned reflex activity before the start of the experiment showed that the time spent on the execution of individual links of the developed drinking habit, on average, was: the latent period of reaction to the conditioned stimulus $-1.2 \pm 0.07$ sec, the time of jumping and running $-3.2 \pm 0.07 \mathrm{sec}$, drinking time - $19.8 \pm 0.17 \mathrm{sec}$, return time to the starting compartment of the chamber was $3.97 \pm 0.09 \mathrm{sec}$. Electrical stimulation of SO, VMH and MM nuclei of the hypothalamus at low parameters of stimulation (60-100 $\mu \mathrm{A}, 5 \mathrm{~Hz}, 0.5 \mathrm{~ms}$ ) did not effect on the performance of the drinking skill. An increase in stimulation parameters $(100-300 \mu \mathrm{A}$,
5-100 Hz, $0.5 \mathrm{~ms}$ ) also did not lead to significant changes in the behavior of animals, with the exception of the latent period of the conditioned reflex, which increased from $1.2 \pm 0.07$ to $3.17 \pm 0.06$ sec. The time spent on running jump, lap up and return remained unchanged and averaged $3.2 \pm 0.07$, respectively; $19.7 \pm 0.15$; $3.9 \pm 0.08 \mathrm{sec}$. The amount of water consumed in the experiment did not change and remained at the background level (100-120 ml).

The conditions of the conditioned reflex described above are presented by the example of stimulation of the VMH of the hypothalamic nucleus. Similar changes in the behavior of animals were observed upon electrical stimulation of the nuclear MM. A somewhat different behavior of rabbits was observed upon stimulation of the SO nucleus of the hypothalamic. Electrical stimulation of the SO nucleus of the hypothalamic caused the appearance of signs of emotional anxiety. In connection with licking and sniffing the starting section of the chamber, the latent period of the reaction slightly increased from $1.2 \pm 0.07$ to $3.23 \pm 0.07 \mathrm{sec}$. The time spent on jumping and running, water consumption and return remained unchanged, which averaged $3.3 \pm 0.07$, respectively; $20.07 \pm 0.15 ; 4.13 \pm 0.09 \mathrm{sec}$.

The registration of the amount of consumed water showed the following: electrostimulation of SO caused additional water consumption in comparison with the background. The amount of water drunk during the entire period of the experiment doubled and amounted to 200-250 ml (Figure 1).

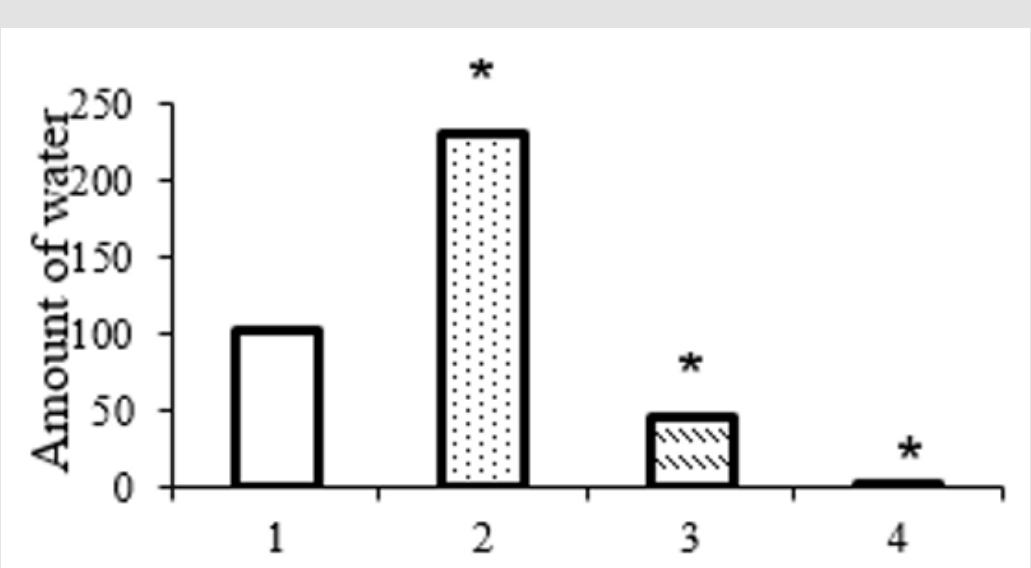

Figure 1: Change in the amount of water consumption as a result of electrostimulation and novocaine blockade of the supraoptic nucleus of the hypothalamus. 1 - background, 2 - after electrical stimulation, 3.4 - after unilateral and bilateral novocaine blockade of the supraoptic nucleus of the hypothalamus, respectively.

Stimulation of the VMH and MM of the hypothalamic nuclei did not interfere with the performance of the developed drinking habit in animals previously deprived of water, the latent period of the reaction to the conditioned stimulus slightly increased. The amount of water consumed did not change in comparison with the background. The introduction of a $5 \%$ solution of novocaine into the VMH and MM of the hypothalamic nucleus did not interfere with the performance of the developed drinking habit. At the same time, the temporal parameters of the skill performance remained at the level of the background indices and were for the VMH: the latent period of reaction to the conditioned stimulus was on average $1.2 \pm 0.07 \mathrm{sec}$, the jump and run from the starting section of the chamber to the target $-3,27 \pm 0.07 \mathrm{sec}$, drinking time $-20.13 \pm$ $0.09 \mathrm{sec}$ and return to the starting compartment $-4.23 \pm 0.7 \mathrm{sec}$. 
Similar data observed in the behavior of animals were obtained after the introduction of a $5 \%$ solution of novocaine into the MM of the hypothalamic nucleus.

A somewhat different behavioral picture was observed with the introduction of $5 \%$ solution of novocaine into the SO of the anterior hypothalamus. The animal reacted to the sound signal with a long latency period: $3.97,90.11$ instead of $1.27 \pm 0.07 \mathrm{sec}$. The time spent on running jump also increased - from $3.23 \pm 0.07$ to $5.5 \pm 0.08 \mathrm{sec}$, water consumption - from $20.07 \pm 0.17$ to $32.5 \pm 0.33 \mathrm{sec}$ and return - from $4.1 \pm 0.1$ to $7.53 \pm 0.1 \mathrm{sec}$. The application of novocaine in So led to a significant decrease in the amount of water consumed, which decreased for the duration of the action of novocaine (40-50 minutes) and amounted to $60-70 \mathrm{ml}$ instead of 120 in the norm. Bilateral novocaine blockade of SO led to a complete inhibition of the performance of the developed drinking skill (Figure 1).

Observation of the behavior of animals revealed the following. Electrical stimulation of the VMH and MM of the hypothalamus did not cause disturbances in the behavior of the animals. Only the latency period of the reaction increased slightly. With electrical stimulation of the nucleus SO, the animals showed signs of emotional anxiety, and when a sound signal was applied, the developed drinking habit was retained, but the amount of water drunk significantly increased (2 times). Anderson [10] observed a similar increase in the drinking reaction upon irritation of the anterior nuclei of the hypothalamus in contrast to the data of other authors, who noted an increase in water consumption during electrical stimulation of the lateral hypothalamus [11], irritation of the preoptic region [12], as well as destruction of the VMH of the hypothalamic nucleus in rats [13].

In our experiments, various effects of novocaine blockade of the studied nuclei of the hypothalamus were revealed. So, if the blockade of VMH and MM did not cause an effect on the developed drinking habit, then even one-sided switching off of the SO of the nucleus caused an increase in all time parameters. The amount of water consumed has significantly decreased. Bilateral application of novocaine to this nucleus led to a complete inhibition of the performance of the developed drinking habit and refusal of water, despite the fact that before coagulation the animals had a pronounced drinking motivation. Complete adipsia and a sharp decrease in water consumption after the destruction of the anterior nuclei of the hypothalamus were observed by a number of authors [10], in the opposite of the data of other researchers who caused adipsia when the lateral hypothalamus was damaged [14], with the joint destruction of the lateral hypothalamus and the lateral preoptic region [15], as well as with damage to the medial hypothalamus. The appearance of thirst upon electrical stimulation of the SO of the anterior hypothalamus and its disappearance with bilateral novocaine blockade of this area, apparently, can be explained by the presence of osmosensitive neurons in the SO, which were found in this nucleus [16] and to which some researchers assign a primary role in the regulation of water consumption [17].

Thus, the results of the studies carried out on electrical stimulation and temporary switching off the SO suggest that the osmoreceptors of the SO of the anterior hypothalamus play a certain role in the processes of the formation of thirst.

\section{References}

1. Artymuk NV, GA Ushakova (2001) Modern concepts of hypothalamic syndrome. Mother and Child in Kuzbass 1: 24-27.

2. Shilkin VV, VI Filimonov (2013) Anatomy according to Pirogov: atlas human anatomy. Moscow: GEOTAR-Media 2: 736.

3. Chernysheva MP, AD Nozdrachev (2017) Neuroendocrine hypothalamus as a homeostat of endogenous time. Journal of Evolutionary Biochemistry and Physiology 53(1): 3-15.

4. IV Zhukovets (2011) Etiology and pathogenesis of hypothalamic dysfunction: a modern view of the problem. Bulletin of physiology and pathology of respiration 42: 96-100.

5. Uvarova EV, EP Khashchenko (2010) Hypothalamic dysfunction: etiopathogenesis and clinical picture (literature review). Reproductive health of children and adolescents 1: 35-47.

6. Wayne AM, T Voznesenskaya (2000) Hypothalamic syndrome. Doctor 4: $12-14$

7. Swaab DS (2003) The Human Hypothalamus: Basic and Clinical Aspects. Part I: Handbook of Clinical Neurology. London 79: 476.

8. Swaab DS (2003) The Human Hypothalamus: Basic and Clinical Aspects. Part II: Handbook of Clinical Neurology. London 80: 597.

9. Nikonova LV, Tishkovsky SV, Butrim OS, Davydchik EV (2019) Hypothalamic syndrome. The role of the hypothalamus in the formation of eating behavior and obesity. Journal of Grodno State Medical University 17(4): 355-360. (Никонова Л В, Тишковский СВ, Бүтрим ОС, Давыдчик Эв (2019) Гипоталамический синдром. Роль гипоталамуса в формировании пищевого поведения и ожирения. Журнал Гродненского Государственного Медицинского Университета, Том 17, № 4).

10. Andersson B, Leksell LY, Lishajko F (1975) Perturbations in fluid balance induced by medially placed forebrain lesions. Brain Research .99(2): 261-275.

11. Mogenson GJ, Stevenson JAF (1967) Drinking induced by electrical stimulation of the lateral hypothalamus. Exptl Neurol 17(2): 119-127.

12. Veszpremi L, Hanusz L, Obal F Benedek Gy (1980) Behavioural effects of localized preoptic heating. Acta physiology, Acad Sci Hung 56(1): 99100 .

13. Kakolewski JW, Deaux E, Christensen J, Case B (1971) Diurnal patterns in water and food intake and body weight changes in rats with hypothalamic lesions. Amer J Physiol 221(3): 711-718.

14. Witt DM, Keller AD, Batsel AL, Lingh JR (1952) Absense of thirst and resultant syndrome associated with anterior hypothalamectomy in the dog. Am J Physol 171(3): 780-798.

15. Almi CR, Weiss ChS (1974) Drinking behaviors: effects of lateral preoptic and lateral hypothalamic destruction. J Physiol and Behav 13(14): 27-53.

16. Abe N, Ebina T, N Ishida (1982) Interferon induction by glycyrrhizin and glycyrrhetinic acid in mice. Microbiol Immunol 26(6): 535-539.

17. Mc Kinley MJ, Blaine EH, Denton DA (1974) Brain osmoreceptors, cerebrospinal electrolyte composition and thirst. J Brain Research 70(3): 532-537. 
ISSN: 2574-1241

DOI: 10.26717/BJSTR.2021.35.005762

Rafiga Mazahir Baghirova. Biomed J Sci \& Tech Res

(C) This work is licensed under Creative BY Commons Attribution 4.0 License

Submission Link: https://biomedres.us/submit-manuscript.php

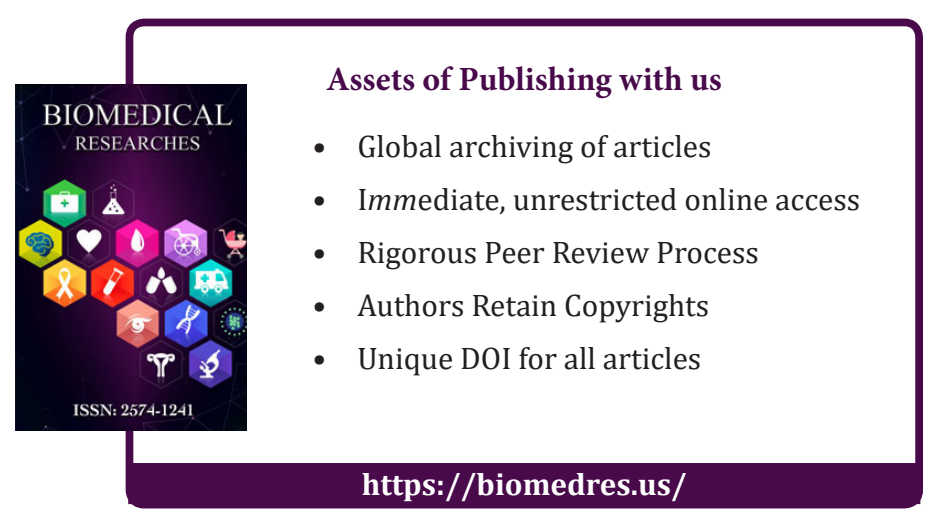

